\title{
Outcomes of long left coronary endarterectomy in patients with diffuse coronary artery disease
}

\author{
Kamaraj Radhakrishnan', Sean D. Galvin², Adam El-Gamel' \\ 'Department of Cardiothoracic Surgery, Waikato Hospital, Hamilton 3400, New Zealand. \\ ${ }^{2}$ Department of Cardiac Surgery, Wellington Regional Hospital, Hamilton 3400, New Zealand.
}

Correspondence to: Prof. Adam El-Gamel, Department of Cardiothoracic Surgery, Cardiothoracic Surgical Unit, Waikato Hospital, Pembroke Street, Private Bag 3200, Hamilton 3240, New Zealand. E-mail: elgamela@waikatodhb.govt.nz

How to cite this article: Radhakrishnan K, Galvin SD, El-Gamel A. Outcomes of long left coronary endarterectomy in patients with diffuse coronary artery disease. Vessel P/us 2019;3:36. http://dx.doi.org/10.20517/2574-1209.2019.23

Received: 8 Jul 2019 First Decision: 2 Aug 2019 Revised: 26 Aug 2019 Accepted: 30 Sep 2019 Published: 24 Oct 2019

Science Editor: Mario F. L. Gaudino Copy Editor: Cai-Hong Wang Production Editor: Jing Yu

\begin{abstract}
Aim: Historically the outcome of left coronary artery endarterectomy (LCAE) has been associated with increased morbidity and mortality when surgeons performed it with coronary artery bypass grafting (CABG). We aim to review outcomes after open LCAE-CABG in patients managed with aggressive dual antiplatelet therapy.
\end{abstract}

Methods: From 1999 to 2007 open LCAE with CABG was performed in 87 patients. We compared the short and long-terms outcomes of 75 propensity-matched conventional CABG patients. Both groups were operated on by a single surgeon.

Results: Sixty-six percent $(66 \% ; n=58 / 87)$ of LCAE group had diffuse atheroma in Left anterior descending artery $(\mathrm{LAD}) ; 31 \%(n=27 / 87)$ involved both LAD and branches of the circumflex artery $(C x) ; 3 \% ;(n=3 / 87)$ involved the $C x$ in isolation. Cross clamp time (43.29 vs. 59.04, $P=0.019)$ and bypass time (57.29 vs. $74.04, P=0.007)$ were significantly higher in the LCAE group. There was no significant difference in early ( $1 \% \mathrm{vs.} 1.3 \%)$ and late mortality ( $4 \%$ vs. $4.5 \%$ at 10 years). The hospital length of stay ( $5.58 \mathrm{vs} .6 .67, P=0.03$ ), was higher in the LACE group when compared with the CABG group. The freedom from angina and long-term survival were not significantly different between the two groups.

Conclusion: Patients undergoing CABG with Left-sided coronary endarterectomy had increased cross-clamp and bypass times with prolonged stay in hospital and increased blood transfusion rates. The mortality, morbidity, longterm survival and freedom from angina are not different when compared to CABG alone. The use of retrograde blood cardioplegia and aggressive antiplatelets may have contributed to the excellent outcome.

cc) (7) The Author(s) 2019. Open Access This article is licensed under a Creative Commons Attribution 4.0 International License (https://creativecommons.org/licenses/by/4.0/), which permits unrestricted use sharing, adaptation, distribution and reproduction in any medium or format, for any purpose, even commercially, as long as you give appropriate credit to the original author(s) and the source, provide a link to the Creative Commons license, and indicate if changes were made.

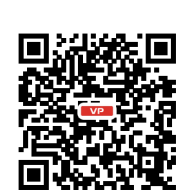


Keywords: Coronary endarterectomy, coronary artery disease

\section{INTRODUCTION}

Primary coronary endarterectomy without coronary artery bypass grafting (CABG) was first introduced in 1957 by Bailey for the treatment of acute myocardial infarction ${ }^{[1-3]}$. Subsequently, endarterectomy was combined with CABG alone, and later by vein patch and left internal mammary (LIMA) bypass of the left anterior descending artery $(\mathrm{LAD})^{[4-8]}$. Initial published reports showed a high incidence of perioperative mortality and ischemia ${ }^{[9-13]}$. This led to reluctance in performing coronary endarterectomy. The adverse outcomes have resulted in some patients with severe and diffuse left-sided disease denied complete surgical revascularization. The use of dual antiplatelet therapy (aspirin and clopidogrel) has been shown to improve graft patency. Which led reduce major adverse cardiovascular events. The combination of both may improve survival following $\mathrm{CABG}^{[14,15]}$. We aim to assess the early and late results of left coronary endarterectomy (LCAE). Which we used as an essential step in CABG. We also combined surgery with dual antiplatelet therapy post-op (aspirin and clopidogrel).

\section{METHODS}

We included Patients with no option for percutaneous coronary intervention (PCI) and were rejected for conventional CABG. The rejection was because angiographically patients had atheroma involving $<80 \%$ of the length of the coronary artery. These patients underwent CABG with LCAE at a university teaching hospital by a single surgeon from February 1999 to September 2007. We identified the patients from a prospectively collected database. We compared this group with a propensity-matched cohort (to allow matching patients characteristics and risk profile) from the same period operated on by the same surgeon in the same hospital. Information regarding pre-operative status was gathered from the clinical database. Also, the clinical notes were reviewed retrospectively for these patients. Post-operative data were obtained from the clinical database, clinic letters and GP surgery data. If the clinical records were not adequate, the patient's general practitioner was contacted by phone or e-mail. Table 1 summarizes the pre-operative patient demographics of the study patients. The mean follow-up of the patients was for five years (Range 0-10 years).

LCAE was performed on occluded or nearly occluded vessels with multiple and long distal stenoses. Patterns of atherosclerosis were identified pre-operatively, but the decision to perform endarterectomy was made intra-operatively. The surgeon decided on technical consideration in combination with angiographic features. Off-pump CABG cases were included in both the groups (CABG $=28 / 75$, LCAE $=13 / 87$ ). The methods of myocardial protection techniques were comparable in both groups. Core temperatures were maintained between 30 degrees to 32 degrees during cardiopulmonary bypass.

All coronary endarterectomies were performed manually. A Watson-Cheyne dissector was used to develop a plane between tunica media and the core of the atheromatous plaque. The site for arteriotomy was chosen, and the decision to do endarterectomy was made if the artery was almost entirely or wholly occluded, or if the vessel wall contained heavily calcified plaques. Arteriotomy was extended as required $(2.5-9 \mathrm{~cm})$ and Watson-Cheyne dissector used to develop the plane, and gentle graduated traction was used to tease off the atheromatous core from the distal end of the vessel [Figure 1]. If the distal end of the atheroma was not tapered, then the arteriotomy was extended until a satisfactory result was obtained, but no attempt was made to extract the atheromatous core from the individual branches of the artery. A vein patch was used in all the cases. The conduit was anastomosed end to side to the vein patch in all the cases. 


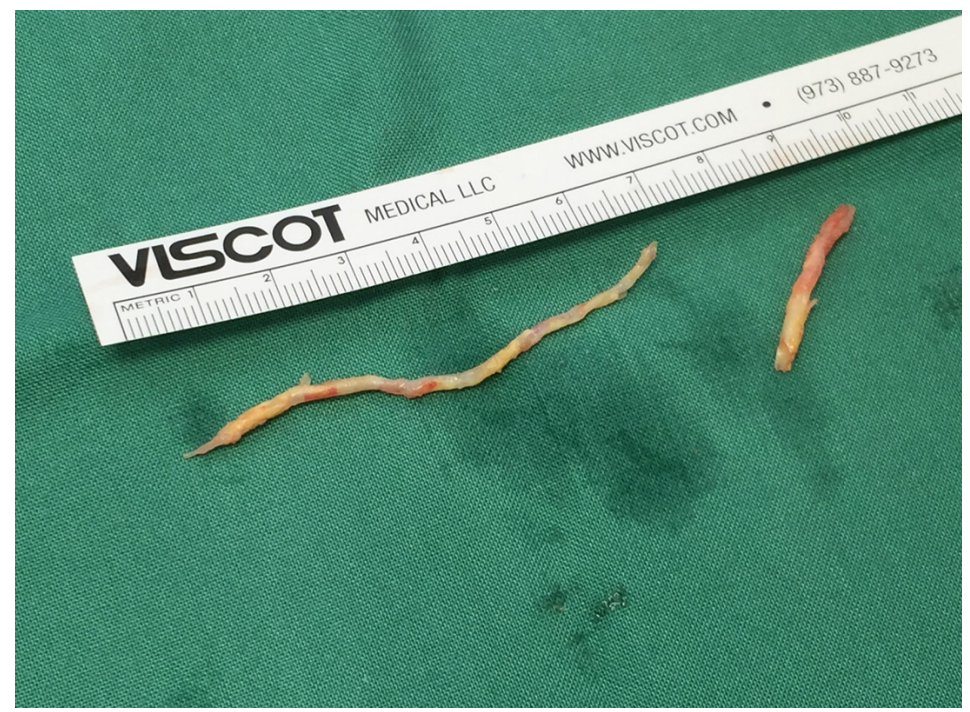

Figure 1. endarterectomy

Table 1. Patient demographics in control and study population

\begin{tabular}{lccc}
\hline Variable & CABG + LCAE $(\boldsymbol{n}=\mathbf{8 7})$ & CABG $(\boldsymbol{n}=\mathbf{7 5})$ & $\boldsymbol{P}$ value \\
\hline Age & $67(37-85)$ & $64(43-84)$ & 0.06 \\
Sex & M 68, F 19 & M 62, F 13 & 0.55 \\
Diabetes Mellitus & $8 / 87$ & $16 / 75$ & 0.04 \\
Hypertension & $48 / 87$ & $35 / 75$ & 0.34 \\
Parsonnet score & $8(0-43)$ & $6.9(0-27)$ & 0.10 \\
Timing of Surgery & & & \\
Elective & 27 & 11 & 0.01 \\
Urgent inpatient & 60 & 62 & 0.02 \\
Emergency & 0 & 2 & 0.21 \\
Salvage & 2 & 0 & 0.49 \\
\hline
\end{tabular}

CABG: coronary artery bypass grafts; LCAE: left coronary artery endarterectomy

As part of our routine clinical practice, all patients undergoing CABG receive dual antiplatelet therapy (DAPT) post-operatively. Aspirin 300 mg is given at 4-6 h post-operatively and $150 \mathrm{mg} / \mathrm{day}$ after that which was recommended to continue lifelong. In addition to aspirin, patients received clopidogrel $300 \mathrm{mg}$ at 4-6 $\mathrm{h}$ post-operatively and $75 \mathrm{mg} /$ day after that, which was recommended to continue for 1-year. In both groups, DAPT was administered if the bleeding was $<150 \mathrm{~mL} / \mathrm{h}$ for the first $4 \mathrm{~h}$ postoperatively.

\section{Statistical analysis}

Statistical significance was designed to test the all or none hypothesis that use of concomitant coronary endarterectomy will not affect the outcome of Coronary artery bypass grafting. Statistical significance was obtained by a $P$-value $<0.05$. Nominal data were analyzed using the Fisher test and interval data using the student $t$-test. Actuarial survival curves were calculated using the Kaplan Meier survival analysis. All statistical analysis was done using the GraphPad Prism statistical package.

\section{RESULTS}

The patient demographics were similar in both the groups as presented in Table 1, except for the incidence of Diabetes Mellitus in the CABG group and increased elective surgery numbers in the LCAE group. 
Table 2. Operative data

\begin{tabular}{|c|c|c|c|}
\hline Variable & CABG + CE $(n=87)$ & CABG $(n=75)$ & $P$ value \\
\hline \multicolumn{4}{|l|}{ Number of grafts } \\
\hline One & 4 & 4 & 1.00 \\
\hline Two & 9 & 16 & 0.08 \\
\hline Three & 42 & 44 & 0.20 \\
\hline Four & 16 & 20 & 0.25 \\
\hline Five & 1 & 1 & 1.00 \\
\hline Arterial grafts & $1.32(0-4)$ & $1.28(0-4)$ & 0.72 \\
\hline Vein grafts & $1.66(0-4)$ & $1.72(0-3)$ & 0.71 \\
\hline IMA used & $89 \%$ & $94 \%$ & 0.31 \\
\hline Cross clamp time (min) & 60.5 & 45.5 & 0.012 \\
\hline Bypass time (min) & 77.2 & 62 & 0.018 \\
\hline \multicolumn{4}{|c|}{ Coronary endarterectomy + vein patch } \\
\hline LAD only & 58 & 0 & \\
\hline$L A D+C x$ & 26 & 0 & \\
\hline Cx only & 3 & 0 & \\
\hline
\end{tabular}

CABG: coronary artery bypass grafts; Cx: circumflex; IMA: internal mammary artery; LAD: left anterior descending; LCAE: left coronary artery endarterectomy

Operative data are presented in Table 2. The number of grafts was similar in both groups. The additional time to perform the grafts, including the endarterectomy, resulted in longer cross-clamp time (60.5 min vs. $45.5 \mathrm{~min}$ ) and longer bypass times $(77.2 \mathrm{~min} v s .62 \mathrm{~min}$ ). LIMA use was slightly higher in the CABG group ( $94 \% v s .89 \%)$. Of the 87 with diffuse coronary atheroma, the lesion distribution was, 58 patients had isolated LAD endarterectomy, three patients had Cx endarterectomy, and 26 patients had both $\mathrm{Cx}$ and LAD endarterectomy. The number of arterial and vein grafts was similar in both groups of patients. All patients undergoing endarterectomy received a vein patch.

\section{Peri-operative complications}

The hospital complications observed are presented in Table 3. There were two patients with low cardiac output $(2.3 \%)$ in the LCAE group, and one patient (1.3\%) had low cardiac output in the immediate postop period in the CABG group. The rate of postoperative bleeding, prolonged ventilation, post-operative arrhythmia's, non-fatal strokes, TIA, renal impairment, chest infection and wound infection were similar in both groups.

\section{Mortality}

Each group had one death within 30 days of surgery. The patient who died in the LCAE group was a 62-year-old female who had a salvage CABG with endarterectomy on cardiopulmonary bypass, but developed vascular embolic phenomenon, stroke and GI bleed leading to death. The death in the CABG group was a 73-year-old male who had an urgent inpatient CABG which was complicated by a post-op chest infection, renal failure, prolonged intubation and death due to respiratory failure.

\section{Hospital resource utilization}

The hospital resource utilization data are presented in Table 4. The period of mechanical ventilation was the same in both groups. The patients with coronary endarterectomy had an increased period of ICU stay 0.37 days (0-14) vs. 0.13 days (0-30) in the CABG group. The blood transfusion was also higher in the Coronary endarterectomy group with an average infusion of $458 \mathrm{~mL}(0-4,134 \mathrm{~mL})$ per patient, as compared to $308 \mathrm{~mL}(0-2,137 \mathrm{~mL})$ in the CABG group. The hospital length of stay for endarterectomy patients was longer compared to those undergoing $\mathrm{CABG}$ alone.

\section{Actuarial survival and follow up}

There was no significant difference in actuarial survival between the two groups, as shown in Figure 1. After a mean follow-up of 5 years, there were four deaths in the LCAE group when compared to 3 deaths 
Table 3. Perioperative complication

\begin{tabular}{|c|c|c|c|}
\hline Characteristics & CABG + CE $(n=87)$ & CABG $(n=75)$ & $P$ value \\
\hline \multicolumn{4}{|l|}{ Deaths } \\
\hline 30 - day & $1(1.1 \%)$ & $1(1.3 \%)$ & 1 \\
\hline Late & $4(4.5 \%)$ & $3(4 \%)$ & 0.7 \\
\hline \multicolumn{4}{|l|}{ Complications } \\
\hline Low cardiac output & $2(2.3 \%)$ & $1(1.3 \%)$ & 0.6 \\
\hline Arrhythmia's & $3(3.4 \%)$ & $2(2.6 \%)$ & 1 \\
\hline Permanent stroke & $1(1.1 \%)$ & 0 & 1 \\
\hline TIA & $3(3.4 \%)$ & $1(1.3 \%)$ & 1 \\
\hline Chest infection & $1(1.1 \%)$ & $2(2.6 \%)$ & 0.5 \\
\hline Prolonged ventilation & $4(4.5 \%)$ & $2(2.6 \%)$ & 0.3 \\
\hline Renal impairment & $2(2.3 \%)$ & $1(1.3 \%)$ & 0.6 \\
\hline Gl bleed & 0 & $1(1.3 \%)$ & 1 \\
\hline Leg wound infection & $1(1.1 \%)$ & $1(1.3 \%)$ & 1 \\
\hline Re-operation for bleeding & $4(4.5 \%)$ & $1(1.3 \%)$ & 0.3 \\
\hline
\end{tabular}

CABG: coronary artery bypass grafts; LCAE: left coronary artery endarterectomy; GI: gastrointestinal; TIA: transient ischaemic attack

Table 4. Hospital resource utilization

\begin{tabular}{lcl}
\hline Category & CABG + CE $(\boldsymbol{n}=\mathbf{8 7})$ & CABG $(\boldsymbol{n}=\mathbf{7 5})$ \\
\hline post-op ventilation hours & $6.96(2-32)$ & $7.01(2-15)$ \\
ICU stay in days & $0.37(0-14)$ & $0.13(0-3)$ \\
Length of hospital stay in days & $6.67(2-19)$ & $5.58(3-11)$ \\
Blood transfusion $(\mathrm{mL})$ & $458(0-4,134)$ & $308(0-2,137)$ \\
\hline
\end{tabular}

CABG: coronary artery bypass grafts; ICU: intensive care unit; LCAE: left coronary artery endarterectomy

in the CABG group. The deaths in the LCAE group occurred after three years in 2 patients and four years in the other two patients. The three deaths in the CABG only group occurred after 2 years, 4 years and five years respectively. The one-year survival was $98.9 \%$, and the 5 -year survival was $95.5 \%$ in the LCAE group [Figure 2].

The freedom from angina was similar in both groups at the end of one year, as shown in Figure 3. There was no statistical difference in the incidence of angina in the post-op period at the end of 10 years follow up.

\section{DISCUSSION}

Despite the excellent results obtained with surgical revascularization, advances in the field of PCI coupled with its less invasive nature have made it the most common interventional treatment strategy for coronary artery disease ${ }^{[16,17]}$. However, patients with complex and diffuse disease may be challenging to entirely surgically revascularize. Complete revascularisation and in particular arterial grafting to the left coronary system has a significant impact on long term survival of patients ${ }^{[1,19]}$. It is, therefore, essential for surgeons to have an effective strategy for grafting patients with diffuse severe obstructive CAD to achieve complete revascularization. In the presence of diffuse disease, open endarterectomy is a surgical adjunct, which can produce good clinical results in these otherwise inoperable patients.

Various methods of coronary endarterectomy have been described. Initially, a closed traction method with primary closure of the arteriotomy was practised ${ }^{[1]}$. Over time the procedure evolved to include patch closure of the arteriotomy combined with LIMA or saphenous vein bypass grafting ${ }^{[6,720,21]}$. In this study, all endarterectomies were performed under direct vision, exposing the whole arterial lumen and side branches and arteriotomy closure with vein patch with subsequent end to side grafting was done in all patients. This has been an effective method, with only one patient requiring further revascularisation 


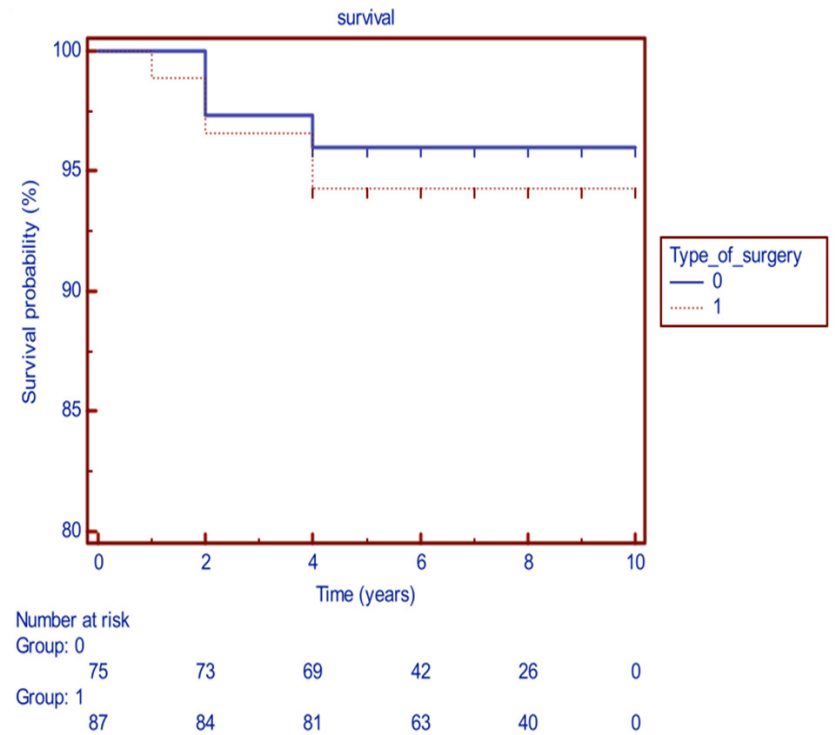

Figure 2. Survival in patients undergoing CABG only (group 0) or CABG combined with coronary endarterectomy (group 1)

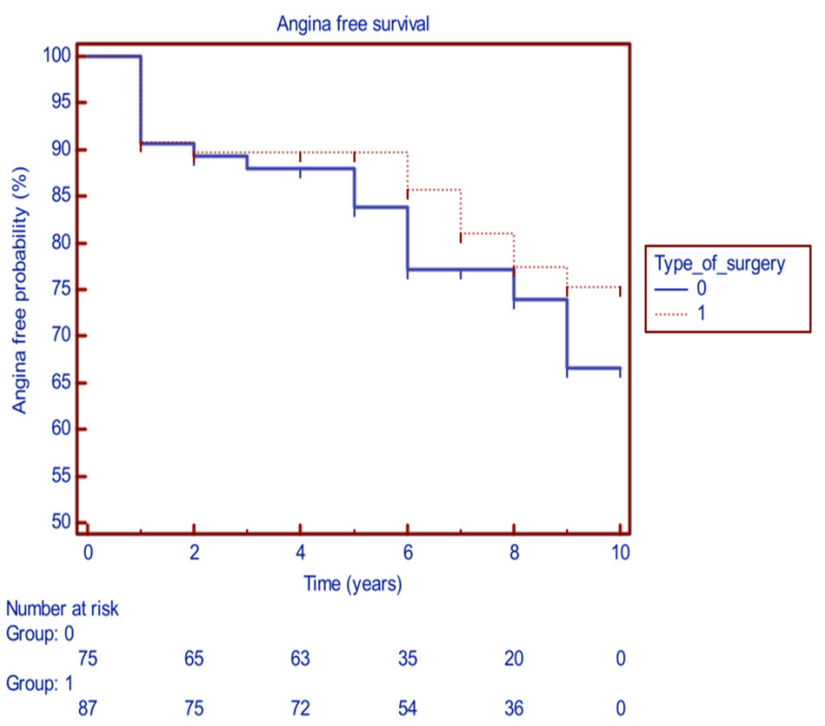

Figure 3. Freedom from angina in patients undergoing CABG only (group 0) or CABG combined with coronary endarterectomy (group 1)

in the immediate post-op period due to poor cardiac output. All patients in the LCAE group had diffuse severe coronary artery disease. The ability to achieve complete revascularization and where possible to use the left internal mammary artery ( $89 \%$ of patients in this study) to bypass the left coronary system has been shown to improve outcomes in patients with CAD. In the LCAE group, complete revascularization likely would not have been possible without the use of adjuvant coronary endarterectomy. Furthermore, in native coronary arteries with multiple sequential obstructive lesions, coronary endarterectomy coupled with vein patching and grafting allows the target vessel to be grafted with a single rather than numerous coronary anastomoses.

The higher incidence of perioperative myocardial ischemia in earlier studies involving technically excellent surgeons was not seen in this study ${ }^{[5,9,15]}$. Two critical factors have likely contributed to improved outcomes in this compared to historical studies: firstly advances in techniques of myocardial protection, in particular, 
the use of retrograde cardioplegia and secondly the use of aggressive post-op anticoagulation with dual antiplatelet therapy. All endarterectomy procedures were performed by an open method, and retrograde cardioplegia was used for flushing out all the debris immediately. During beating heart surgery, the endarterectomy was performed after application of a sling proximally, and retrograde flow used to flush the debris before vein patching and anastomosis. Early and midterm graft failure may be due to thrombosis of the graft itself or of the native vessel. Historically LCE was associated with an increased incidence of graft failure and perioperative myocardial infarction ${ }^{[22,23]}$. This is likely due to exposure of the prothrombotic and platelet aggregating promoting components of the vessel wall following endarterectomy. Dual antiplatelet therapy, possibly by reducing early thrombotic events and platelet clumping, has been shown to improve graft patency in off-pump surgery, following acute coronary syndromes, when multiple vein grafts are used and in native vessel disease vessels with reduced runoff. This has translated into improved clinical outcomes in these groups. Besides, aggressive antiplatelet administration immediately post-op with aspirin and clopidogrel has been proven to be safe and effective after coronary artery surgery ${ }^{[1424-26]}$. We commenced all our patients on clopidogrel, and aspirin immediately following surgery and continued on Clopidogrel for 1-year post-op along with lifelong aspirin.

Ideally, angiographic confirmation of graft patency would have been preferred, but the freedom from angina in our study (91.8\% at 1year and $79.4 \%$ at 10 years) along with a low incidence of perioperative ischaemic events indirectly shows that this strategy is a valuable additional benefit for these patients.

Our results, coupled with those from other centres, suggest that coronary endarterectomy can be accomplished safely and acceptably when applied in a particular way ${ }^{[27,28]}$. In this study, we have shown comparable results of endarterectomy with the CABG only group when comparing long term survival and freedom from angina. Although numerically morbidity in the endarterectomy group was slightly higher than control, it did not have a lasting effect on long term outcome. We propose the use of left-sided endarterectomy as a safe adjutant in dealing with diffusely diseased coronary vessel disease, especially when long term prognosis is essential.

\section{DECLARATIONS}

\section{Authors' contributions}

Collected and analysed the data: Radhakrishnan K

Supervised and helped writing the manuscripte: Galvin SD

Operting senior surgeon: El-Gamel A

\section{Availability of data and materials}

Data collected from King's college and Waikato dendrite data bases.

\section{Financial support and sponsorship}

None.

\section{Conflicts of interest}

All authors declare that there are no conflicts of interest.

\section{Ethical approval and consent to participate}

The study has ethics approval from both king's College hospital local ethics committee and waikato hospital. All patients were consented for the study as per regulation.

\section{Consent for publication}

Not applicable. 


\section{Copyright}

(c) The Author(s) 2019.

\section{REFERENCES}

1. Bailey CP, May A, Lemmon WM. Survival after coronary endarterectomy in man. J Am Med Assoc 164, 641-646 (1957).

2. Sabiston DC. Coronary endarterectomy. Proc R Soc Med 1961;54:353-4.

3. Nardi GL, Shaw RS. Emergency coronary endarterectomy. Dis Chest 1963;44:193-6.

4. Effler DB, Sones FM, Favaloro R, Groves LK. Coronary endarterotomy with patch-graft reconstruction: clinical experience with 34 cases. Ann Surg 1965;162:590-601.

5. Parsonnet V, Gilbert L, Gielchinsky I, Bhaktan EK, Atherlay T. Coronary endarterectomy: an analysis of its role in aortocoronary bypass. Cardiovasc Dis 1976;3:51-60.

6. Fundarò P, Di Biasi P, Santoli C. Coronary endarterectomy combined with vein patch reconstruction and internal mammary artery grafting: experience with 18 patients. Tex Heart Inst J 1987;14:389-94.

7. Ladowski JS, Schatzlein MH, Underhill DJ, Peterson AC. Endarterectomy, vein patch, and mammary bypass of the anterior descending artery. Ann Thorac Surg 1991;52:1187-9.

8. Christenson JT, Simonet F, Schmuziger M. Extensive endarterectomy of the left anterior descending coronary artery combined with coronary artery bypass grafting. Coron Artery Dis 1995;6:731-7.

9. Halim MA, Qureshi SA, Towers MK, Yacoub MH. Early and late results of combined endarterectomy and coronary bypass grafting for diffuse coronary disease. Am J Cardiol 1982;49:1623-6.

10. Shapira OM, Akopian G, Hussain A, Adelstein M, Lazar HL, et al. Improved clinical outcomes in patients undergoing coronary artery bypass grafting with coronary endarterectomy. Ann Thorac Surg 1999;68:2273-8.

11. Eryilmaz S, Inan MB, Eren NT, Yazicioglu L, Corapcioğlu T, et al. Coronary endarterectomy with off-pump coronary artery bypass surgery. Ann Thorac Surg 2003;75:865-9.

12. Kunt AS, Darcin OT, Demirbag R, Andac MH. Coronary endarterectomy with beating heart in patients with diffuse atheromatous coronary artery disease and poor ventricular function: early and midterm results. Heart Surg Forum 2005;8:E124-8.

13. Sørensen R, Abildstrøm SZ, Hansen PR, Hvelplund A, Andersson C, et al. Efficacy of post-operative clopidogrel treatment in patients revascularized with coronary artery bypass grafting after myocardial infarction. J Am Coll Cardiol 2011;57:1202-9.

14. Gao G, Zheng Z, Pi Y, Lu B, Lu J, et al. Aspirin plus clopidogrel therapy increases early venous graft patency after coronary artery bypass surgery a single-center, randomized, controlled trial. J Am Coll Cardiol 2010;56:1639-43.

15. Livesay JJ, Cooley DA, Hallman GL, Reul GJ, Ott DA, et al. Early and late results of coronary endarterectomy. Analysis of 3,369 patients. J Thorac Cardiovasc Surg 1986;92:649-60.

16. Yap CH, Yan BP, Akowuah E, Dinh DT, Smith JA, et al. Does prior percutaneous coronary intervention adversely affect early and mid-term survival after coronary artery surgery? JACC Cardiovasc Interv 2009;2:758-64.

17. Lenzen MJ, Boersma E, Bertrand ME, Maier W, Moris C, et al. Management and outcome of patients with established coronary artery disease: the Euro Heart Survey on coronary revascularization. Eur Heart J 2005;26:1169-79.

18. Bell MR, Gersh BJ, Schaff HV, Holmes DR Jr, Fisher LD, et al. Effect of completeness of revascularization on long-term outcome of patients with three-vessel disease undergoing coronary artery bypass surgery. A report from the Coronary Artery Surgery Study (CASS) Registry. Circulation 1992;86:446-57.

19. Jones EL, Craver JM, Guyton RA, Bone DK, Hatcher CR Jr, et al. Importance of complete revascularization in performance of the coronary bypass operation. Am J Cardiol 1983;51:7-12.

20. Taşdemir O, Kiziltepe U, Karagöz HY, Yamak B, Korkmaz S, et al. Long-term results of reconstructions of the left anterior descending coronary artery in diffuse atherosclerotic lesions. J Thorac Cardiovasc Surg 1996;112:745-54.

21. Gill IS, Beanlands DS, Boyd WD, Finlay S, Keon WJ. Left anterior descending endarterectomy and internal thoracic artery bypass for diffuse coronary disease. Ann Thorac Surg 1998;65:659-62.

22. Beretta L, Lemma M, Vanelli P, DiMattia D, Bozzi G, et al. Coronary “open” endarterectomy and reconstruction: short- and longterm results of the revascularization with saphenous vein versus IMA-graft. Eur J Cardiothorac Surg 1992;6:382-6; discussion 387.

23. Sachweh JS, Messmer BJ, Groetzner J, Vom Dahl J, Fausten B, et al. Left anterior descending coronary artery: long-term angiographic results of CABG with endarterectomy. J Cardiovasc Surg (Torino) 2007;48:633-40.

24. Chan V, Kulik A, Bourke ME, Ressler L, Mesana TG, et al. Clopidogrel is safe early after on- and off-pump coronary artery bypass surgery. J Card Surg 2007;22:493-7.

25. Kayacioglu I, Gunay R, Saskin H, Idiz M, Sensoz Y, et al. The role of clopidogrel and acetylsalicylic acid in the prevention of earlyphase graft occlusion due to reactive thrombocytosis after coronary artery bypass operation. Heart Surg Forum 2008;11:E152-7.

26. Sun JC, Teoh KH, Lamy A, Sheth T, Ellins ML, et al. Randomized trial of aspirin and clopidogrel versus aspirin alone for the prevention of coronary artery bypass graft occlusion: the preoperative aspirin and postoperative antiplatelets in coronary artery bypass grafting study. Am Heart J 2010;160:1178-84.

27. Schmitto JD, Kolat P, Ortmann P, Popov AF, Coskun KO, et al. Early results of coronary artery bypass grafting with coronary endarterectomy for severe coronary artery disease. J Cardiothorac Surg 2009;4:52.

28. Vohra HA, Kanwar R, Khan T, Dimitri WR. Early and late outcome after off-pump coronary artery bypass graft surgery with coronary endarterectomy: a single-center 10-year experience. Ann Thorac Surg 2006;81:1691-6. 